\title{
The Effect of Early-Life Education on Later-Life Mortality
}

\author{
Dan A. Black, University of Chicago, NORC, and IZA \\ $\mathrm{Yu}$-Chieh Hsu, University of Chicago and NORC \\ Lowell J. Taylor, Carnegie Mellon University, NORC, and IZA
}

December 19, 2012

\begin{abstract}
Many studies link cross-State policy variation in compulsory schooling laws to the early-life human capital accumulation of individuals born in the early twentieth century U.S., thus providing a plausible way to investigate the causal impact of education on various lifetime outcomes. We use this strategy to estimate the effect of education on older-age mortality. Our key innovation is to combine U.S. Census data and the complete Vital Statistics records to form precise mortality estimates by sex, birth cohort, and birth State. In turn we find that virtually all of the variation in these mortality rates is captured by cohort effects and State effects alone, making it impossible to reliably tease out any additional impact due to changing educational attainment induced by State-level changes in compulsory schooling.
\end{abstract}

This work is preliminary and incomplete; comments welcome. Our research is supported by support from the Eunice Kennedy Shriver National Institute of Child Health and Human Development. The content is solely the responsibility of the authors and does not necessarily represent the official views of the Eunice Kennedy Shriver National Institute of Child Health and Human Development or the National Institutes of Health. 


\section{Introduction}

A large literature documents a strong correlation between education and health outcomes. ${ }^{1}$ Many scholars have suggested that the relationship is likely causal. Cutler and Lleras-Muney (2010), for example, provide persuasive evidence about a number of pathways by which education might improve health: highly educated people have higher income and better insurance, higher cognitive ability, and stronger social networks, all of which contribute to better health behaviors.

Even so, it is difficult to cleanly demonstrate a causal relationship between education and mortality. One possible way to proceed - exemplified by the pioneering work of Lleras-Muney (2005) - is to exploit changes in compulsory schooling laws as a means of finding plausibly exogenous variation for the purpose of identifying the impact of education on subsequent mortality. Using an IV strategy based on changes in compulsory schooling laws in the early twentieth century U.S., Lleras-Muney (2005) estimates a large causal impact of education on mortality; she finds that among whites "one additional year of schooling reduces ten-year mortality rates by about $60 \%$."

Several additional studies have followed Lleras-Muney's lead. Among recent examples, Albouy and Lequien (2009) use French data to examine two successive reforms in compulsory education laws. Analyses using regression discontinuity (RD) and instrumental variables (IV) lead the authors to conclude that "survival rates at 50 and 80 years old do not seem to be affected by years of schooling between 13 and 16." Similarly, Clark and Royer (forthcoming) examine the relationship between education and health in the United Kingdom, using 1947 and 1972 British compulsory school laws reforms. Also implementing RD and IV strategies, they find no sizable effect of education on mortality. Finally, Meghir, Palme, and Simeonova's (2012) study of compulsory education reform in Sweden shows that increased education appears to have contributed to limited gains in mortality among women from such preventable causes as lung cancer and liver cirrhosis, and some delay in mortality among men from their forties to their fifties. Overall, though, they find that "the reform had very small effects on overall health up to age 60" (which is the oldest age they could evaluate with their data). ${ }^{2}$

The papers cited in the previous paragraph suggest that the causal effects of education on mortality rates are sufficiently small that they are difficult to estimate in many settings. What is required, first of all, is a policy shift substantial enough to affect meaningful changes in completed schooling among a relatively large number of people. Beyond that, though, there are two common problems for researchers: First, for some populations under study, mortality is sufficiently rare that it is difficult to tease out a small impact of education on

\footnotetext{
${ }^{1}$ As Grossman (2000) states, many studies show that "years of formal schooling completed is the most important correlate of good health. This finding emerges whether health levels are measured by mortality rates, morbidity rates, self-evaluation of health status, or physiological indicators of health, and whether the units of observation are individuals or groups. The studies also suggest that schooling is a more important correlate of health than occupation or income, the two other components of socioeconomic status."

${ }^{2}$ Lochner (2011) provides thoughtful overview of recent papers on the causal impact of education on mortality and on health more generally.
} 
mortality even with large samples and accurate data. Second, mortality is often measured with imprecision. The following examples are illustrative.

Consider, first, Meghir, Palme, and Simeonova's (2012) study of mortality in Sweden. These authors evaluate a policy change - school reforms implemented at the municipal level in Sweden between 1949 and 1962 - that induces a reasonably large response in completed education. But while they have impressive and accurate data, based on population registers of more than 670,000 men and 650,000 women, their data allow analysis only at ages 60 and younger, and in the Swedish setting this means their data include only approximately 32,000 deaths for men and 20,000 deaths among women.

At the opposite end of the spectrum, consider Lleras-Muney's (2005) analysis. Her work also is based on important changes in compulsory schooling laws (in her case, at the State level), which have meaningful impacts on the attainment of education. ${ }^{3}$ By analyzing mortality from 1960 through 1980 for white men and women born in the U.S. between 1901 and 1925, she has millions of deaths to account for. The problem is that her research design requires death rates for cohort $\times$ gender $\times$ State of birth cells, which she estimates using one percent public use samples from the Census. Thus, while the population under study is much larger than in Meghir, et al. (2012), the key variable of interest - the mortality rate - is measured with massively less precision.

The imprecision of the mortality estimates used as the dependent variable in LlerasMuney (2005) means that inferences drawn may also be somewhat tenuous. Thus, for example, despite the fact that her estimated effect size is large, statistical power is sufficiently low that in the key regressions results are not statistically significant for men and women separately.

Our innovation here is to incorporate far more data than has been employed in previous work. In particular, like Lleras-Muney, we examine cohorts of white men and women born 1901-1925 in the U.S., but our primary focus is on mortality during the years 1980 to 1990, during which we can construct mortality estimates using the complete death counts from Vital Statistics records, as those data include State of birth on an on-going basis from 1978 forward. Mortality is reasonably high for our study cohorts, who are aged approximately 55-89. Thus we use several million death records in constructing our mortality estimates. A key challenge is appropriately estimating denominators for calculating death rates at the cohort by State of birth level. We use a simple generalized method of moments (GMM) procedure that optimally combines Census and Vital Statistics data for this purpose.

Ideally we would like to use our GMM methodology to look at mortality at younger ages as well. While State of birth is not generally available for public records prior to 1978, we fortunately did find data for the years 1960-1963. Thus we can conduct our analyses for those years also (at which time individuals in our study cohorts are aged 35 to 62).

Having estimated mortality rates quite precisely for the population under study, we proceed to estimate the impact of schooling on mortality using compulsory schooling law changes as instruments. Our most important finding is that when we use our highly-precise

\footnotetext{
${ }^{3}$ For more on compulsory schooling laws in the U.S., see, for example, Angrist and Krueger (1991), Acemoglu and Angrist (2000), Goldin and Katz (2008), and Stephens and Yang (2012).
} 
mortality estimates, a simple OLS regression, with cohort fixed effects, State fixed effects, and region by cohort fixed effects, gives an $R^{2}$ greater than 0.995 for both men and women. ${ }^{4}$ Thus there is very little variation to be explained; only an extraordinary quasi-experiment can be expected to allow us to detect an effect of schooling changes on mortality against the existing trends.

Nonetheless we attempt IV analyses using conventional methods. Inferences are somewhat sensitive to specification, and also they depend on the way schooling laws are coded, i.e., whether we use variables constructed by Lleras-Muney (2005), Goldin and Katz (2008), or Stephens and Yang (2012). However, in all cases the estimated coefficients are very close to zero. In short, we find no persuasive evidence of a substantial causal impact of schooling on mortality.

\section{GMM Estimates of Mortality Using Census and Vi- tal Statistics Data}

In the empirical work that follows we are relying on year-to-year State-level educational policy variation as a means of generating variation in educational attainment, which we then hope to map into older-age mortality. So the first step is to find a way to estimate mortality by birth State and birth cohort. Also, because mortality rates differ substantially by sex, we need to estimate these separately for men and women. We restrict attention to whites.

As noted above, Lleras-Muney (2005) adopts a clever and straightforward approach. The idea is to calculate ten-year mortality rates, using U.S. Decennial Census samples. These data have all the required elements. For example, suppose we want to estimate mortality for men born in Georgia in 1912 (denoted here as group $i$ ) over the period 1980 through 1990. Let $N_{i}^{0}$ be the number of individuals in this cohort in 1980, a Census year, and $N_{i}^{1}$ be the comparable number from the following Decennial Census, taken in 1990. Then if we assume that there is no net migration of this group,

$$
\frac{\left(N_{i}^{0}-N_{i}^{1}\right)}{N_{i}^{0}}
$$

is the ten-year mortality rate (from, roughly, age 68 to 78). We do not observe the required elements in (1); instead we can use as our estimator

$$
\frac{\left(\omega^{0} S_{i}^{0}-\omega^{1} S_{i}^{1}\right)}{\omega^{0} S_{i}^{0}}
$$

where $S_{i}^{0}$ and $S_{i}^{1}$ are respective sample counts and $\omega^{0}$ and $\omega^{1}$ are the appropriate inflation factors. Thus, for example, if we are using a 1-in-20 sample in both periods, these factors are 20 .

Estimator (2) is likely to be quite noisy when samples are small. Here we suggest that improvements are possible if we have a count from Vital Statistics data of the number of

\footnotetext{
${ }^{4}$ Indeed, the $R^{2}$ statistics are well over 0.99 with the cohort effects and State effects alone.
} 
individuals in group $i$ who have died between time 0 and time 1 . Let $D_{i}$ be such a count, and suppose that it has been accurately recorded. Then mortality is $D_{i} / N_{i}^{0}$. Our goal is to use available data efficiently for the purpose of estimating $N_{i}^{0}$, which we can then use as a base to form this mortality estimate. Black, et al. (2011) derive a simple generalized method of moments (GMM) procedure for handling the problem. We outline the basic idea here.

Given our data structure we have two moment restrictions: ${ }^{5}$

$$
\begin{aligned}
\mathrm{E}\left\{\omega^{0} S_{i}^{0}-N_{i}^{0}\right\} & =0, \\
\mathrm{E}\left\{\omega^{1} S_{i}^{1}+D_{i}-N_{i}^{0}\right\} & =0 .
\end{aligned}
$$

The hope is to find an estimator that fits these restrictions well.

A starting point is to minimize

$$
\left[\begin{array}{ll}
N_{i}^{0}-\omega^{0} S_{i}^{0} & N_{i}^{0}-\omega^{1} S_{i}^{1}-D_{i}
\end{array}\right]\left[\begin{array}{ll}
1 & 0 \\
0 & 1
\end{array}\right]\left[\begin{array}{c}
N_{i}^{0}-\omega^{0} S_{i}^{0} \\
N_{i}^{0}-\omega^{1} S_{i}^{1}-D_{i}
\end{array}\right]
$$

which leads to a minimum distance estimator,

$$
\hat{N}_{i}^{0}=\frac{1}{2}\left(\omega^{0} S_{i}^{0}\right)+\frac{1}{2}\left(\omega^{1} S_{i}^{1}+D_{i}\right)
$$

This in turn can be used as a first step to form a GMM estimator. The next step is to undertake a minimization exercise, such as the one given in (4), but in which the matrix in the interior of (4) replaces the identity matrix with $W^{-1}$, the inverse of the covariance matrix from the vector of "moment restrictions," which in our case is

$$
\begin{aligned}
& W=\mathrm{E}\left\{\left[\begin{array}{c}
N_{i}^{0}-\omega^{0} S_{i}^{0} \\
N_{i}^{0}-\omega^{1} S_{i}^{1}-D_{i}
\end{array}\right]\left[\begin{array}{ll}
N_{i}^{0}-\omega^{0} S_{i}^{0} & N_{i}^{0}-\omega^{1} S_{i}^{1}-D_{i}
\end{array}\right]\right\} \\
& =\left[\begin{array}{cc}
\left(\omega^{0}\right)^{2} S^{0} p_{i}^{0}\left(1-p_{i}^{0}\right) & 0 \\
0 & \left(\omega^{1}\right)^{2} S^{1} p_{i}^{1}\left(1-p_{i}^{1}\right)
\end{array}\right] \text {, }
\end{aligned}
$$

where $p_{i}^{0}$ and $p_{i}^{1}$ are, respectively, the probability in period 0 that an observation from the complete sample $S^{0}$ is a member of group $i$, and the analogous probability in period $1{ }^{6}$ The terms in $W$ are easy to find as our particular problem entails draws from two independent

\footnotetext{
${ }^{5}$ Our restrictions assume that $D_{i}$, the death counts for individuals in group $i$, have been accurately recorded in Vital Statistics records. If this number is thought to be recorded with error, and the error process can be modeled, we would instead have three moment restrictions.

${ }^{6}$ That is, $p_{i}^{0}=\frac{N_{i}^{0}}{N^{0}}$ and $p_{i}^{1}=\frac{N_{i}^{1}}{N^{1}}$. We of course don't directly observe $p_{i}^{0}$ or $p_{i}^{1}$, since $N_{i}^{0}$ and $N_{i}^{1}$ are unknown.
} 
binomial processes. ${ }^{7}$ With a bit of algebra we can show that the resulting estimator is

$$
\begin{aligned}
\hat{\hat{N}}_{i}^{0} & =\left[\frac{\left(\left(\omega^{0}\right)^{2} S^{0} \hat{p}_{i}^{0}\left(1-\hat{p}_{i}^{0}\right)\right)^{-1}}{\left(\left(\omega^{0}\right)^{2} S^{0} \hat{p}_{i}^{0}\left(1-\hat{p}_{i}^{0}\right)\right)^{-1}+\left(\left(\omega^{1}\right)^{2} S^{1} \hat{p}_{i}^{1}\left(1-\hat{p}_{i}^{1}\right)\right)^{-1}}\right] \omega^{0} S_{i}^{0} \\
& +\left[\frac{\left(\left(\omega^{1}\right)^{2} S^{1} \hat{p}_{i}^{1}\left(1-\hat{p}_{i}^{1}\right)\right)^{-1}}{\left(\left(\omega^{0}\right)^{2} S^{0} \hat{p}_{i}^{0}\left(1-\hat{p}_{i}^{0}\right)\right)^{-1}+\left(\left(\omega^{1}\right)^{2} S^{1} \hat{p}_{i}^{1}\left(1-\hat{p}_{i}^{1}\right)\right)^{-1}}\right]\left(\omega^{1} S_{i}^{1}+D_{i}\right),
\end{aligned}
$$

where, as a practical matter, $p_{i}$ are replaced with $\hat{p}_{i}$ - estimates derived in the first stage. As in (5), we are using a weighted sum of two consistent estimates of $N_{i}^{0}$ for our estimator, but in the GMM case we use asymptotically optimal weights.

Finally, having found the GMM estimate of $N_{i}^{0}$, our estimate of the mortality rate for group $i$ from time 0 to time 1 is

$$
d_{i}=\frac{D_{i}}{\hat{\hat{N}}_{i}^{0}} .
$$

We estimate these objects for several thousand birth State $\times$ birth cohort $\times$ sex cells. They form the basis for the analysis that follows. Unfortunately, State of birth is a recorded element for Vital Statistics death records on an on-going basis only after 1978. So in the work that follows, we use estimates of ten-year mortality for 1980 to 1990. As for earlier periods, we do have birth State for data from the years 1960-1963, so for those years we estimate mortality for a shorter period, using the 1960 Census data to form appropriate denominators.

Tables 1 and 2 are intended to give some sense of our GMM mortality estimates, which combine Census data and Vital Statistics records, and can be expected to compare to the Census-only estimates. First, from Table 1 we notice that some of the cells we are working with are quite small - just a few hundred observations (estimated with far fewer than 100 observations, given our 5 percent sample). Thus we expect the estimates of mortality to be rather noisy using the Census-only approach, particularly for the small cells. Table 2 shows that in general the correlation between the Census-only and GMM estimates is very high overall-greater than 0.95. This is as expected. However, also as expected, the correlation is much lower for smaller cells, i.e., is only approximately 0.70 for cells below the 10th percentile. This means that the Census-only approach is introducing a great deal of noise, relative to the efficient GMM approach, for smaller cells.

Table 3 gives summary statistics for our mortality rates. Panel A shows the 4-year mortality rate for 1960-1963. Mortality is quite low, which is not surprising given that the cohorts we are evaluating are reasonably young (aged 35-62). The ten-year mortality rates given in Panel B are of course much higher, as they are for a longer period and at older ages (55-89). For comparison sake we also give Census-only estimates (where possible). Notice

\footnotetext{
${ }^{7}$ Conceptually, the Census finds the entire population, and samples a fraction of these individuals for public use releases. Then, for example, in period 0 each of these individuals has a $p_{i}^{0}$ probability of belonging to group $i$ and a $1-p_{i}^{0}$ probability of being in some other group. Estimates of the first moment have variance $S^{0} p_{i}^{0}\left(1-p_{i}^{0}\right)$.
} 
that the standard deviation of the Census-only estimates is slightly higher than the estimates that combine Census and Vital Statistics data, as is expected given that the former estimates are noisier.

\section{The Impact of Schooling on Older-Age Mortality}

Our approach closely parallels Lleras-Muney's (2005) —work that uses the 1960, 1970, and $19801 \%$ U.S. Census samples to evaluate mortality of white individuals who were born in 1901-1925 in the U.S. Recall that in that work, State-level measures of the expansions of compulsory schooling laws over the 1915-1939 period are used as instruments for education. Her results indicate that an additional year of schooling lowers ten-year mortality rates by about 60 percent, but results were not statistically significant for men and women separately, and subsequent analysis has given researchers some pause about the robustness of that finding. ${ }^{8}$ Our hope here is that with our GMM mortality estimates derived from Census and Vital Statistics data - estimates that are more precise than the Census-only estimates used in previous work - we can sharpen inference.

\subsection{Data}

For our primary analysis, mortality estimates are based on data from the 1980 and 1990 5\% public use samples of the U.S. Census and annual 1980-1990 detailed mortality files from the U.S. Vital Statistics. As discussed, we also conduct analysis using mortality from 1960-1963 using data from the Census and Vital Statistics.

We include cases where age, State of birth, and education are imputed by the Census. Like Lleras-Muney, we topcode the years of completed education at 18 years for consistency. We use the weighted samples with the personal weights assigned by the Census. Summary statistics for completed education are given in Table 4. Notice that educational attainment is higher when measured in 1980. This might reflect that a larger fraction of the earliest cohorts have died, and that they generally had lower levels of education. It might also reflect imprecision in recall about one's educational attainment, and that such imprecision is increasing in age and is predominantly one-sided (as in Black, Sanders, and Taylor, 2003).

As for measures of the compulsory schooling laws, we use data provided by Lleras-Muney in our initial analysis. The same is true for data on other State-level characteristics.

\subsection{Results}

The basic research design is very simple. We begin by forming mortality estimates, as described above, for birth State $\times$ birth cohort for 48 States for the 1901-1925 cohorts of white men and women. The resulting estimates are used as the dependent variable in a

\footnotetext{
${ }^{8}$ See Lleras-Muney (2006) and Mazumder (2008, 2010). Lochner (2011) also expresses some skepticism about the magnitude of Lleras-Muney's (2005) findings.
} 
regression that includes as an explanatory variable the average level of completed education for the corresponding group.

Let $m_{c s}$ be the log mortality rate for the period under study (the ten-year rate for 19801990 or the four-year rate for 1960-1963) for cohort $c$ (single-year birth cohorts 1901 through $1925)$ in State $s$, and let $E_{c s}$ be the corresponding average level of completed education for that same cell. ${ }^{9}$ Then in a baseline differences-in-differences specification we would have

$$
m_{c s}=\omega_{s}+\delta_{c}+\alpha E_{c s}+\varepsilon_{c s}
$$

i.e., the log mortality rate for a demographic group is estimated to be a function of average education in a regression that includes cohort fixed effects and State fixed effects. We estimate such regressions using weighted least squares, where weights are constructed using cell sizes. Regressions are estimated separately for men and women. As for standard error calculations, we cluster at the birth cohort by State level.

As a starting point, to our baseline regression we also add region $\times$ cohort indicators and a series of State-level covariates used by Lleras-Muney (2005). These include variables (measured at age 14): \% urban population, $\%$ foreign born, $\%$ black, $\%$ of people employed in manufacturing, annual manufacturing wage in real terms, average value of farm per acre, number of doctors per capita, educational expenditures per capita, and number of school buildings per square mile. In short, we begin by replicating the Lleras-Muney approach as closely as possible, so as to facilitate comparison. Results are given in Table 5.

In the first column of Table 5 we report results when we use the Census-only mortality estimates (for 1980-1990). We find that the IV estimate of the impact of education on later-life mortality is negative for both men and women, but is statistically significant only for women (and only at the 0.10 in this latter case). Of course, the Census-only estimates are not our preferred mortality estimates; we do not use them further in the analysis that follows.

Moving to the second column of Table 5, we report results when we use the mortality estimates derived by combining Census data and Vital Statistics data. There are two important differences we wish to highlight. First, the standard errors on our "years of education" coefficients drop substantially - for men, from 0.127 to 0.019 , and for women, from 0.210 to 0.023. Second, $R^{2}$ statistics increase substantially - for men, from 0.889 to 0.996, and for women, from 0.837 to 0.997 .

In fact, even if we omit the explanatory variable "years of education" from our regression, the $R^{2}$ statistics are extremely high, 0.996 for men and 0.997 for women. Put another way, virtually all of the variation in mortality can be accounted for by cohort effects, State effects, and region by cohort effects. In this light, it is quite remarkable that in column (2) of Table 5 we also find a precisely estimated, reasonable effect of education on mortality. For both men and women, on the basis of our IV estimates, we would infer that one extra year of education reduces mortality by approximately five percent. ${ }^{10}$

\footnotetext{
${ }^{9}$ Thus $m_{c s}=\ln \left(d_{c s}\right)$, where $d_{c s}$ is defined in (8) for the 1980-1990 data.

${ }^{10}$ In the first stage, education seems to be reasonably well explained by the State-level compulsory school laws (as coded by Lleras-Muney, 2005). Note that F statistics are in the vicinity of 7 .
} 
Moving to the third column of Table 5 we find that we are unable to detect a statistically significant effect of education on mortality at younger ages (i.e., as measured in 1960-1963).

The inclusion of cohort and State effects is natural in our regression. After all, mortality rates clearly increase with age, necessitating the cohort effects. Also, the instruments for completed education - compulsory schooling laws - are implemented at the State level, so inclusion of State effects is standard. It is less clear why we would want to "control for" other State-level demographic characteristics given that we have State effects already in the regression. Similarly, there is a somewhat ad hoc feel to the inclusion of region $\times$ cohort effects, though it is hard to see why such variables would, on their own, cause problems beyond reducing the power of the analysis. ${ }^{11}$

We do a little more exploration with the 1980-1990 mortality results in Table 6, and do the same for the 1960-1963 results in Table 7. In particular, we explore the consequence of dropping the State-level demographic covariates and region $\times$ cohort variables. It is somewhat disconcerting to see that results for men, Panel A of Table 6, seem to be quite sensitive to our change in specification, in particular to omitting the region by cohort fixed effects. Indeed, our IV estimates changes sign (going from -0.06 to 0.08). For women, results don't change much when we drop State-level covariates and region by cohort fixed effects, but the estimated coefficients are no longer statistically significant.

As for our results from 1960-1963, Table 7 shows that we estimate a statistically significant effect of education on mortality only in one of our regressions; we estimate a negative impact, for women, in a specification without the State-level covariates and region by cohort fixed effects.

With all this in mind, we turn to another important issue: As we have noted, many papers use compulsory schooling laws as instruments in various analyses. Over time, scholars have updated the coding of these laws. We are grateful to authors of two such studies - Goldin and Katz (2008) and Stephens and Yang (2012) - for providing us with their coding of compulsory schooling laws. It is important to know if results are sensitive to these updates. This is particularly true given results from Stephens and Yang (2012) indicating that estimates of the return to schooling vary substantially depending on the coding of compulsory schooling laws.

Table 8 summarizes correlations between the instruments and the observed years of education, and also the correlations of the instruments among themselves. The Stephens-Yang coding provides the highest correlation with years of education for all four of our groupingmen, as measured in 1980 and 1960, and women, as measured in these same years. Of course, Stephens and Yang (2012) have the benefit of being able to build on the work of the previous authors. Also, we note that in undertaking this analysis we are now using only cohorts 1905-1925, rather than starting with 1901, as Stephens-Yang only provide data for those cohorts. ${ }^{12}$

With three sets of instruments now in place, we now repeat our IV analyses. Table 9

\footnotetext{
${ }^{11}$ In any event, we also tried using Census division $\times$ cohort effects as an alternative, and this made little difference to the results.

${ }^{12}$ See also Stephens and Yang (2012), who show that in analysis extending over more cohorts their coding of schooling laws increases first-stage fit substantially, in comparison to previous efforts.
} 
reports results when we include region by cohort fixed effects. Results are disquieting. We find that some estimates are consistent with the expected negative impact-increased schooling reduces mortality - but that others are unexpectedly positive. ${ }^{13}$ It is likely that part of the problem is due to weak instruments (see the relatively low F statistics). Even if scholars were subsequently to determine that one set of instruments is "correct" while the others are "incorrect" (a somewhat unlikely eventuality), we still would not have a confidence-inspiring results to report.

It is tempting to conclude that at least we have shown that the causal impact of education on mortality is small. However, notice that in our regressions fixed effects "explain" a great deal of the variation in morality, and some of that variation might be due to State- and regional-level differences in educational policies. We can say that the local average treatment effects (LATE) - due to changes in the compulsory schooling laws - are likely very small. Even our conclusion that the LATE is very small comes with important caveats. Our LATE estimates hinge crucially on an exclusion restriction with regard to compulsory schooling law changes, and it is easy to construct plausible scenarios in which violations might occur. For example, school reform within States might have been more likely during periods of prosperity, and that prosperity itself might have been associated with better health among children.

Having said all that, our finding that the LATE is likely very small is useful. It echoes results from Clark and Royer's (forthcoming) study of mortality based on British compulsory school laws. It also calls into question Lleras-Muney's (2005) finding of a large impact of education on mortality.

Our final point concerns the nature of our inferential problem. Our work underscores the evident value of incorporating better data. In our case we find that with good data on mortality, very little variation in mortality remains to be explained by education (or any other factors) once we condition on State and region $\times$ cohort estimates.

\section{Conclusion}

Schooling appears to be a key correlate of older-age mortality. In this paper we seek to provide evidence about the extent to which this important relationship is causal. In particular, we exploit the fact that changes in State-level mandatory schooling laws had important effects on completed schooling for white men and women born in the early twentieth century. While changes in schooling laws - as coded in three important papers (Lleras-Muney, 2005; Goldin and Katz, 2008; and Stephens and Yang, 2012) - do influence educational attainment for individuals born in the early twentieth century U.S., we do not find that such variation appears to have a large effect on mortality. Despite the fact that we have assembled very precise mortality estimates for our regressions, our findings do not even allow us to make a definitive statement about the direction of the impact of education on mortality.

\footnotetext{
${ }^{13}$ Similarly, if we omit the region by cohort fixed effects we continue find some statistically significant positive coefficients and some statistically significant negative coefficients. Inclusion of the State-level demographic covariates makes little difference.
} 
A great deal about links between education and mortality is not well understood. ${ }^{14}$ Our research underscores the difficulties researchers are likely to encounter if they focus on compulsory schooling law changes as a way of learning about these links. At least in the case of U.S. mortality, other research designs will be needed to make further headway.

${ }^{14}$ A good discussion of outstanding issues is found in Cutler and Lleras-Muney (2010). 
Table 1: Estimated Cell Sizes (Sex by Age by State), 1980

\begin{tabular}{l|ccccccc}
\hline percentile & min & 10 th & 25 th & 50 th & 75 th & 90 th & max \\
\hline$S_{i}^{1980}$ & 240 & 1,970 & 4,500 & 10,130 & 19,370 & 30,990 & 96,060 \\
\hline
\end{tabular}

Note: Data are for white men and women, born 1901-1925, in the 5 percent public use sample of the 1980 Census. 
Table 2: Correlations Between the Census-Only Mortality Estimates and GMM Estimates Using Census and Vital Statistics Data, 1980-1990, by 1980 Cell Size

\begin{tabular}{l|cc}
\hline$S_{i}^{1980}$ & Correlation Between Estimates & $\mathrm{n}$ \\
\hline$\leq 10$ th percentile & 0.703 & 240 \\
$\leq 25$ th percentile & 0.854 & 603 \\
$\leq 50$ th percentile & 0.928 & 1200 \\
$\leq 75$ th percentile & 0.946 & 1800 \\
$\leq 90$ th percentile & 0.955 & 2160 \\
All & 0.959 & 2400 \\
\hline Notes: Data are from the 1980 and 1990 public use samples of \\
the U.S. Census and Vital Statistics. In all cases correlations are \\
weighted by $S_{i}^{1980}$. There are 2400 cells in total: 2 sexes by 25 co- \\
horts (1901-1925) by 48 States.
\end{tabular}


Table 3: Summary Statistics, Mortality Rates for 1901-1925 Cohorts

A. Estimate for 1960-1963

\begin{tabular}{lcccccccc} 
& \multicolumn{3}{c}{ Men } & & \multicolumn{3}{c}{ Women } \\
\cline { 2 - 4 }$d_{c s}$, Census and Vital Statistics & 0.026 & 0.018 & 1200 & & 0.013 & & \\
\cline { 2 - 4 } $\ln \left(d_{c s}\right)$, Census and Vital Statistics & -3.907 & 0.704 & 1200 & & -4.565 & 0.614 & 1199
\end{tabular}

B. Estimates for 1980-1990

$d_{c s}$, Census and Vital Statistics

\begin{tabular}{ccc}
\multicolumn{3}{c}{ Men } \\
\hline Mean & Std. Dev. & $\mathrm{n}$ \\
\hline 0.340 & 0.158 & 1200 \\
-1.185 & 0.459 & 1200 \\
0.368 & 0.177 & 1200 \\
-1.126 & 0.531 & 1197
\end{tabular}

\begin{tabular}{ccc}
\multicolumn{3}{c}{ Women } \\
\hline Mean & Std. Dev. & $\mathrm{n}$ \\
\hline 0.227 & 0.131 & 1200 \\
-1.639 & 0.552 & 1200 \\
0.253 & 0.151 & 1200 \\
-1.558 & 0.673 & 1184
\end{tabular}

Notes: The 1960-1963 estimates use Vital Statistics records for numerators and 1960 Census data for denominators. We are missing data for one observation, women born in Nevada in 1904. The 1980-1990 estimates that use Census and Vital Statistics data are constructed using GMM (see text). Census-only estimates are as in Lleras-Muney (2005). For a small number of observations estimates are non-positive. These are dropped when we report log mortality rates. All statistics are weighted using personal weights provided by IPUMS. 
Table 4: Summary Statistics, Years of Education, 1901-1925 Cohorts

A. Measured in 1960

\begin{tabular}{|c|c|c|c|c|c|c|}
\hline & \multicolumn{3}{|c|}{ Men } & \multicolumn{3}{|c|}{ Women } \\
\hline & Mean & Std. Dev. & $\mathrm{n}$ & Mean & Std. Dev. & $\mathrm{n}$ \\
\hline ears of Completed Education & 10.47 & 1.10 & 1200 & 10.57 & 0.84 & 1199 \\
\hline
\end{tabular}

B. Measured in 1980

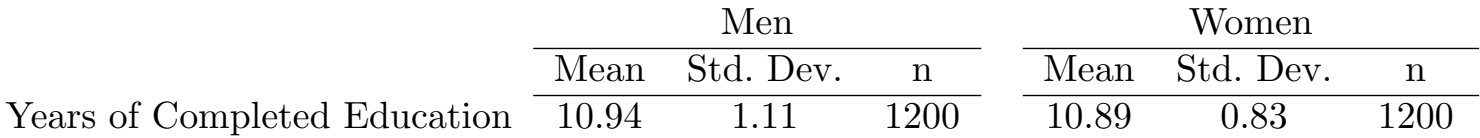

Note: Census data, 1960 and 1980. Weighted statistics are calculated using U.S. Census samples with personal weights provided by IPUMS. Data for white men and women born in 1901-1925 in 48 U.S. States $(\mathrm{n}=2400)$. For 1960, we miss white women born in 1904 in Nevada. 
Table 5: The Effect of Education on Mortality with the Lleras-Muney Specification

\begin{tabular}{|c|c|c|c|}
\hline \multicolumn{4}{|l|}{ A. Men } \\
\hline & $\begin{array}{c}\text { Census Only } \\
1980-1990\end{array}$ & $\begin{array}{c}\text { Census/Vital Stat. } \\
\text { 1980-1990 }\end{array}$ & $\begin{array}{c}\text { Census/Vital Stat. } \\
\text { 1960-1963 }\end{array}$ \\
\hline \multirow[t]{2}{*}{ Years of education (OLS) } & -0.026 & -0.005 & -0.005 \\
\hline & $(0.033)$ & $(0.006)$ & $(0.010)$ \\
\hline \multirow[t]{2}{*}{ Years of education (IV) } & -0.065 & $-0.056^{* * *}$ & 0.027 \\
\hline & $(0.127)$ & $(0.019)$ & $(0.054)$ \\
\hline Cohort fixed effects & Yes & Yes & Yes \\
\hline State fixed effects & Yes & Yes & Yes \\
\hline Region by cohort fixed effects & Yes & Yes & Yes \\
\hline Nine State-level covariates & Yes & Yes & Yes \\
\hline$R^{2}$ for OLS regression & 0.889 & 0.996 & 0.984 \\
\hline First-stage F-stat for IV & $7.72^{* * *}$ & $7.75^{* * *}$ & $4.62^{* * *}$ \\
\hline $\mathrm{n}$ & 1,197 & 1,200 & 1,200 \\
\hline \multicolumn{4}{|l|}{ B. Women } \\
\hline & Census Only & Census/Vital Stat. & Census/Vital Stat. \\
\hline & 1980-1990 & 1980-1990 & 1960-1963 \\
\hline \multirow[t]{2}{*}{ Years of education (OLS) } & -0.027 & $-0.012^{* *}$ & $-0.030^{* *}$ \\
\hline & $(0.063)$ & $(0.006)$ & $(0.013)$ \\
\hline \multirow[t]{2}{*}{ Years of education (IV) } & $-0.373^{*}$ & $-0.052^{* *}$ & 0.013 \\
\hline & $(0.210)$ & $(0.023)$ & $(0.059)$ \\
\hline Cohort fixed effects & Yes & Yes & Yes \\
\hline State fixed effects & Yes & Yes & Yes \\
\hline Region by cohort fixed effects & Yes & Yes & Yes \\
\hline Nine State-level covariates & Yes & Yes & Yes \\
\hline$R^{2}$ for OLS regression & 0.837 & 0.997 & 0.973 \\
\hline First-stage F-stat for IV & $7.12^{* * *}$ & $6.76^{* * *}$ & $3.95^{* * *}$ \\
\hline $\mathrm{n}$ & 1,184 & 1,200 & 1,199 \\
\hline
\end{tabular}

Notes: Birth cohorts, 1901-1925. The dependent variable is the log mortality rate. Regressions use Lleras-Muney's instruments for compulsory schooling laws. Clustered standard errors in parentheses (clustered at the birth cohort by State level). Statistical significance: ${ }^{* * *} p<0.01$, ${ }^{* *} p<0.05,{ }^{*} p<0.10$. 
Table 6: The Effect of Education on Mortality, 1980-1990, Alternative Specifications

\begin{tabular}{|c|c|c|c|}
\hline \multicolumn{4}{|l|}{ A. Men } \\
\hline \multirow[t]{2}{*}{ Years of education (OLS) } & -0.005 & -0.009 & $0.018^{* * *}$ \\
\hline & $(0.006)$ & $(0.006)$ & $(0.006)$ \\
\hline Years of education (IV) & $\begin{array}{c}-0.056^{* * *} \\
(0.019)\end{array}$ & $\begin{array}{c}-0.062^{\text {*** }} \\
(0.020)\end{array}$ & $\begin{array}{c}0.076^{* * *} \\
(0.022)\end{array}$ \\
\hline Cohort fixed effects & Yes & Yes & Yes \\
\hline State fixed effects & Yes & Yes & Yes \\
\hline Region by cohort fixed effects & Yes & Yes & No \\
\hline Nine State-level covariates & Yes & No & No \\
\hline$R^{2}$ for OLS regression & 0.996 & 0.996 & 0.994 \\
\hline First-stage F-stat for IV & $7.75^{* * *}$ & $7.55^{* * *}$ & $8.10^{* * *}$ \\
\hline $\mathrm{n}$ & 1,200 & 1,200 & 1,200 \\
\hline \multicolumn{4}{|l|}{ B. Women } \\
\hline & (1) & $(2)$ & $(3)$ \\
\hline Years of education (OLS) & $\begin{array}{c}-0.012^{* *} \\
(0.006)\end{array}$ & $\begin{array}{l}-0.007 \\
(0.006)\end{array}$ & $\begin{array}{l}-0.006 \\
(0.006)\end{array}$ \\
\hline Years of education (IV) & $\begin{array}{c}-0.052^{* *} \\
(0.023)\end{array}$ & $\begin{array}{l}-0.034 \\
(0.024)\end{array}$ & $\begin{array}{l}-0.029 \\
(0.019)\end{array}$ \\
\hline Cohort fixed effects & Yes & Yes & Yes \\
\hline State fixed effects & Yes & Yes & Yes \\
\hline Region by cohort fixed effects & Yes & Yes & No \\
\hline Nine State-level covariates & Yes & No & No \\
\hline$R^{2}$ for OLS regression & 0.997 & 0.997 & 0.996 \\
\hline First-stage F-stat for IV & $6.76^{* * *}$ & $6.40^{* * *}$ & $12.69^{* * *}$ \\
\hline $\mathrm{n}$ & 1,200 & 1,200 & 1,200 \\
\hline $\begin{array}{l}\text { Notes: Birth cohorts, } 1901-19 \\
\text { year mortality rate, } 1980-199( \\
\text { Muney's instrument. Clustere } \\
\text { birth cohort by State level). } \\
{ }^{*} p<0.10 \text {. }\end{array}$ & $\begin{array}{l}\text { The depe } \\
\text { alculated } \\
\text { andard er } \\
\text { tistical sig }\end{array}$ & $\begin{array}{l}\text { variable } \\
\text { GMM. Reg } \\
\text { parenthe } \\
\text { ce: } * * * p\end{array}$ & $\begin{array}{l}\text { og of the } 1 \\
\text { s use Llera } \\
\text { stered at tl } \\
{ }^{* *} p<0.0\end{array}$ \\
\hline
\end{tabular}


Table 7: The Effect of Education on Mortality, 1960-1963, Alternative Specifications

\begin{tabular}{|c|c|c|c|}
\hline A. Men & $(1)$ & $(2)$ & $(3)$ \\
\hline \multirow[t]{2}{*}{ Years of education (OLS) } & -0.005 & 0.003 & -0.002 \\
\hline & $(0.010)$ & $(0.010)$ & $(0.012)$ \\
\hline \multirow[t]{2}{*}{ Years of education (IV) } & 0.027 & 0.055 & 0.085 \\
\hline & $(0.054)$ & $(0.048)$ & $(0.065)$ \\
\hline Cohort fixed effects & Yes & Yes & Yes \\
\hline State fixed effects & Yes & Yes & Yes \\
\hline Region by cohort fixed effects & Yes & Yes & No \\
\hline Nine State-level covariates & Yes & No & No \\
\hline$R^{2}$ for OLS regression & 0.984 & 0.983 & 0.977 \\
\hline First-stage F-stat for IV & $4.62^{* * *}$ & $5.61^{* * *}$ & $5.95^{* * *}$ \\
\hline $\mathrm{n}$ & 1,200 & 1,200 & 1,200 \\
\hline \multicolumn{4}{|l|}{ B. Women } \\
\hline & (1) & $(2)$ & $(3)$ \\
\hline \multirow[t]{2}{*}{ Years of education (OLS) } & $-0.030^{* *}$ & $-0.029^{* *}$ & $-0.053^{* * *}$ \\
\hline & $(0.013)$ & $(0.014)$ & $(0.014)$ \\
\hline \multirow[t]{2}{*}{ Years of education (IV) } & 0.013 & 0.006 & $-0.118^{*}$ \\
\hline & $(0.059)$ & $(0.060)$ & $(0.070)$ \\
\hline Cohort fixed effects & Yes & Yes & Yes \\
\hline State fixed effects & Yes & Yes & Yes \\
\hline Region by cohort fixed effects & Yes & Yes & No \\
\hline Nine State-level covariates & Yes & No & No \\
\hline$R^{2}$ for OLS regression & 0.973 & 0.973 & 0.968 \\
\hline First-stage F-stat for IV & $3.95^{* * *}$ & $4.37^{* * *}$ & $7.46^{* * *}$ \\
\hline $\mathrm{n}$ & 1,199 & 1,199 & 1,199 \\
\hline
\end{tabular}

Notes: Birth cohorts, 1901-1925. The dependent variable is the log of the 4year mortality rate, 1960-1963, calculated using Census and Vital Statistics data. Regressions use Lleras-Muney's instrument. Clustered standard errors in parentheses (clustered at the birth cohort by State level). Statistical significance: ${ }^{* * *} p<0.01,{ }^{* *} p<0.05,{ }^{*} p<0.10$. 
Table 8: Correlations Between Completed Education and Instruments for Compulsory Schooling Laws

\begin{tabular}{|c|c|c|c|c|}
\hline & Years of Education & Lleras-Muney & Goldin-Katz & Stephens-Yang \\
\hline Years of Education & 1.0000 & - & - & - \\
\hline Lleras-Muney & 0.3473 & 1.0000 & - & - \\
\hline Goldin-Katz & 0.3203 & 0.9084 & 1.0000 & - \\
\hline Stephens-Yang & 0.5476 & 0.5998 & 0.6073 & 1.0000 \\
\hline \multicolumn{5}{|l|}{ B. Men, 1960} \\
\hline & Years of Education & Lleras-Muney & Goldin-Katz & Stephens-Yang \\
\hline Years of Education & 1.0000 & - & - & - \\
\hline LLeras-Muney & 0.3551 & 1.0000 & - & - \\
\hline Goldin-Katz & 0.3204 & 0.8938 & 1.0000 & - \\
\hline Stephens-Yang & 0.5541 & 0.5994 & 0.6010 & 1.0000 \\
\hline \multicolumn{5}{|l|}{ C. Women, 1980} \\
\hline & Years of Education & Lleras-Muney & Goldin-Katz & Stephens-Yang \\
\hline Years of Education & 1.0000 & - & - & - \\
\hline Lleras-Muney & 0.3498 & 1.0000 & - & - \\
\hline Goldin-Katz & 0.3244 & 0.8991 & 1.0000 & - \\
\hline Stephens-Yang & 0.5707 & 0.5981 & 0.6030 & 1.0000 \\
\hline \multicolumn{5}{|l|}{ D. Women, 1960} \\
\hline & Years of Education & Lleras-Muney & Goldin-Katz & Stephens-Yang \\
\hline Years of Education & 1.0000 & - & - & - \\
\hline Lleras-Muney & 0.3430 & 1.0000 & - & - \\
\hline Goldin-Katz & 0.3116 & 0.8924 & 1.0000 & - \\
\hline Stephens-Yang & 0.5492 & 0.5947 & 0.5993 & 1.0000 \\
\hline
\end{tabular}

Notes: Years of education are calculated using Census data. Instruments are from LlerasMuney (2005), Goldin and Katz (2008), and Stephens and Yang (2012). Correlations weighted by $S_{i}^{1980}$ or $S_{i}^{1960}$ (cell size in the Census). $n=2016$ (2 sexes, 21 cohorts, and 48 States). 
Table 9: The Effect of Education on Mortality, IV Analyses Using Different Instruments

\begin{tabular}{|c|c|c|c|c|c|c|}
\hline \multicolumn{7}{|l|}{ A. Men } \\
\hline & \multicolumn{3}{|c|}{ GMM, 1980-1990 } & \multicolumn{3}{|c|}{ Vital Statistic/Census, 1960-1963 } \\
\hline Instruments & Lleras-Muney & Goldin-Katz & Stephens-Yang & Lleras-Muney & Goldin-Katz & Stephens-Yang \\
\hline \multirow[t]{2}{*}{ Years of education (IV) } & $-0.035^{*}$ & -0.004 & $0.056^{* *}$ & 0.045 & 0.043 & 0.060 \\
\hline & $(0.020)$ & $(0.031)$ & $(0.027)$ & $(0.061)$ & $(0.062)$ & $(0.068)$ \\
\hline Cohort fixed effects & Yes & Yes & Yes & Yes & Yes & Yes \\
\hline State fixed effects & Yes & Yes & Yes & Yes & Yes & Yes \\
\hline Region by cohort fixed effects & Yes & Yes & Yes & Yes & Yes & Yes \\
\hline First-stage F-statistic & $15.22^{* * *}$ & $3.94^{* * *}$ & $3.48^{* * *}$ & $4.43^{* * *}$ & $4.68^{* * *}$ & $2.49^{* * *}$ \\
\hline $\mathrm{n}$ & 1,008 & 1,008 & 1,008 & 1,008 & 1,008 & 1,008 \\
\hline \multicolumn{7}{|l|}{ B. Women } \\
\hline & \multicolumn{3}{|c|}{ GMM, $1980-1990$} & \multicolumn{3}{|c|}{ Vital Statistic/Census, 1960-1963 } \\
\hline Instruments & Lleras-Muney & Goldin-Katz & Stephens-Yang & Lleras-Muney & Goldin-Katz & Stephens-Yang \\
\hline Years of education (IV) & -0.042 & $-0.070^{* *}$ & 0.022 & 0.019 & -0.094 & -0.118 \\
\hline & $(0.028)$ & $(0.034)$ & $(0.044)$ & $(0.064)$ & $(0.081)$ & $(0.090)$ \\
\hline Cohort fixed effects & Yes & Yes & Yes & Yes & Yes & Yes \\
\hline State fixed effects & Yes & Yes & Yes & Yes & Yes & Yes \\
\hline Region by cohort fixed effects & Yes & Yes & Yes & Yes & Yes & Yes \\
\hline First-stage F-statistic & $5.81^{* * *}$ & $4.91^{* * *}$ & $1.63^{*}$ & $5.73^{* * *}$ & $3.37^{* * *}$ & $2.06^{* *}$ \\
\hline $\mathrm{n}$ & 1,008 & 1,008 & 1,008 & 1,008 & 1,008 & 1,008 \\
\hline
\end{tabular}

Notes: Birth cohorts from 1905-1925. Regressions with log 10-year GMM death rate, 1980-1990 and log 4-year Vital Statistic/Census death rate, 1960-1963 as the dependent variables. Clustered standard errors in parentheses (clustered at the birth cohort by State level). Statistical significance: ${ }^{* * *} p<0.01,{ }^{* *} p<0.05,{ }^{*} p<0.1$. 


\section{References}

Acemoglu, Daron, and Joshua Angrist, 2001. "How Large are the Social Returns to Education? Evidence from Compulsory Schooling Laws," in Ben Bernanke and Kenneth Rogoff, eds., NBER Macroeconomics Annual 2000, volume 15.

Albouy, Valerie, and Laurent Lequien, 2009. "Does Compulsory Education Lower Mortality?" Journal of Health Economics, 28(1), 155-168.

Angrist, Joshua D., and Alan B. Krueger, 1991. "Does Compulsory School Attendance Affect Schooling and Earnings?" Quarterly Journal of Economics, 106(4), 979-1014.

Black, Dan A., Yu-Chieh Hsu, Seth G. Sanders, and Lowell J. Taylor, 2011. "Estimating Mortality by State of Birth and Race Using Census and Vital Statistics Data," Manuscript, Carnegie Mellon University.

Black, Dan A., Seth G. Sanders, and Lowell J. Taylor, 2003. "Measurement of Higher Education in the Census and Current Population Survey," Journal of the American Statistical Association, 98(463), 545-554.

Clark, Damon, and Heather Royer, forthcoming, "The Effect of Education on Adult Health and Mortality: Evidence from Britain," American Economic Review.

Cutler, David, and Adriana Lleras-Muney, 2010. "Understanding Differences in Health Behaviors by Education ," Journal of Health Economics, 29(1), 1-28.

Goldin, Claudia, and Lawrence F. Katz, 2008. "Mass Secondary Schooling and the State: The Role of State Compulsion in the High School Movement," NBER Chapters, in: Understanding Long-Run Economic Growth: Geography, Institutions, and the Knowledge Economy, page 275-310, National Bureau of Economic Research, Inc.

Grossman, Michael, 1972. "On the Concept of Health Capital and the Demand for Health," The Journal of Political Economy, 80(2), 223-255.

Grossman, Michael, 1972. "The Demand for Health: A Theoretical and Empirical Investigation," Columbia University Press, New York.

Grossman, Michael, 2000. "The Human Capital Model," In Anthony J. Culyer and Joseph P. Newhouse, editors, Handbook of Health Economics, volume 1, Part 1, chapter 7, pages 347-408. Elsevier B.V.

Grossman, Michael, 2006. "Education and Nonmarket Outcomes," In E. Hanushek and F. Welch, editors, Handbook of the Economics of Education, volume 1, chapter 10, pages 577-633. Elsevier B.V.

Grossman, Michael, and Robert Kaestner, 1997. "Effects of Education on Health," In Jere R. Behrman and Nevzer Stacey, editors, The social benefits of education, chapter 4, pages 69-123. University of Michigan Press, Ann Arbor.

Lleras-Muney, Adriana, 2005. "The Relationship between Education and Adult Mortality in the United States," Review of Economic Studies, 72(1), 189-221.

Lleras-Muney, Adriana, 2006. "Erratum: The Relationship between Education and Adult Mortality in the United States," Review of Economic Studies, 73(3), 847.

Lochner, Lance, 2011. "Non-Production Benefits of Education: Crime, Health, and Good Citizenship," NBER Working Paper No. 16722. 
Mazumder, Bhashkar, 2008. "Does Education Improve Health? A Reexamination of the Evidence from Compulsory Schooling Laws," Economic Perspectives, 32(2), 2-17.

Mazumder, Bhashkar, 2010. "Erratum: Does Education Improve Health? A Reexamination of the Evidence from Compulsory Schooling Laws,".

Meghir, Costas, Marten Palme, and Emilia Simeonova, 2012. "Education, Health and Mortality: Evidence from A Social Experiment," NBER Working Paper No. 17932.

Stephens, Melvin Jr., and Dou-Yan Yang, 2012. "Schooling Laws, School Quality, and the Returns to Schooling," Working Paper, University of Michigan. 